\title{
Rapid diagnosis of Gram negative pneumonia by assay of endotoxin in bronchoalveolar lavage fluid
}

\author{
Jérôme Pugin, Raymond Auckenthaler, Olga Delaspre, Elisabeth van Gessel, \\ Peter M Suter
}

\begin{abstract}
Background Diagnosis of ventilator associated pneumonia can be made by quantitative cultures of bronchoalveolar lavage fluid or of protected specimen brushings, though cultures require $24-48$ hours to provide results. In $80 \%$ of cases aerobic Gram negative bacteria are the cause.
\end{abstract}

Methods A rapid diagnostic method of assessing the endotoxin content of lavage fluid by Limulus assay is described. Forty samples of lavage fluid were obtained from patients with multiple trauma requiring mechanical ventilation for a prolonged period. Pneumonia was diagnosed on the basis of clinical, radiological, and bacteriological findings, including quantitative cultures of lavage fluid.

Results A relation was observed between the concentration of endotoxin in lavage fluid and the quantity of Gram negative bacteria. The median endotoxin content of lavage fluid in Gram negative bacterial pneumonia was 15 endotoxin units (EU)/ml; the range observed in individual patients was 6 to $>150 \mathrm{EU} / \mathrm{ml}$. In patients with pneumonia due to Gram positive cocci and in non-infected patients the median endotoxin level was 0.17 (range $\leqslant 0.06$ to 2) $\mathrm{EU} / \mathrm{ml}$. An endotoxin level greater than or equal to $6 \mathrm{EU} / \mathrm{ml}$ distinguished patients with Gram negative bacterial pneumonia from colonised patients and from those with pneumonia due to Gram positive cocci.

Conclusion The measurement of endotoxin in lavage fluid is a rapid (less than two hours) and accurate diagnostic method. It should allow specific and early treatment of Gram negative bacterial pneumonia.

Division of Surgical Intensive Care

J Pugin

E van Gessel

P M Suter

Division of Infectious Diseases

R Auckenthaler

O Delaspre

University Hospital of Geneva, CH-1211

Geneva 4, Switzerland

Reprint requests to:

Professor P M Suter

Accepted 15 November 1991 in critically ill patients. Gram negative bacteria cause more than $80 \%$ of cases of ventilator associated pneumonia and are associated with a higher mortality than other bacteria. ${ }^{1}$ Endotoxin, a membrane component of Gram negative bacteria, can be measured by chromogenic Limulus assay lysate. The test is sensitive, specific, and easy to perform, and takes less than two hours. ${ }^{4}$ Endotoxinaemia is difficult to detect $^{5}$ because free endotoxin levels are lower than in more heavily infected samples, such as urine and cerebrospinal, peritoneal, or amniotic fluid, where the Limulus assay showed good diagnostic yield. ${ }^{6}$ We investigated the relation between endotoxin content and the results of quantitative cultures of lavage fluid and its potential value for the diagnosis of Gram negative bacterial pneumonia.

\section{Methods}

Patients mainly with multiple trauma or head injury and requiring prolonged intubation (median 7 days), and at risk for developing ventilator associated pneumonia, were studied prospectively. After a short period of preoxygenation with fractional inspired oxygen $\left(\mathrm{FIO}_{2}\right) \quad 1.0$ and intravenous sedation with midazolam and morphine we performed bronchoalveolar lavage in orotracheally intubated patients using a fibrescope through a swivel adaptor (Bodai suction-safe Swivel Y, Sontek Medical, Hingham, Massachusetts) with pulse oximetry monitoring. The fibrescope was wedged in'an area corresponding to a localised infiltrate on the chest radiograph. In cases of diffuse or no infiltrate, the right inferior or middle lobe was lavaged. Two aliquots of 50 $\mathrm{ml}$ of sterile saline were used, yielding an average of $30 \mathrm{ml}$ of returned fluid, which was divided into aliquots and stored at $-70^{\circ} \mathrm{C}$ in endotoxin free tubes. Forty lavage samples were obtained prospectively from 28 patients. Pneumonia was diagnosed on the basis of a clinical pulmonary infection score, which included the following: fever, volume and nature of tracheal secretions, arterial oxygenation, peripheral blood leucocytosis, culture of tracheobronchial aspirate, and chest radiograph features. ${ }^{7}$ Each variable was scored 0,1 or 2 . When these are summed the clinical pulmonary infection score varies from 0 (no signs of pneumonia) to 12 (pronounced signs of pneumonia). Patients were considered to have pneumonia when the clinical pulmonary infection score was 7 or more. ${ }^{7}$ This scoring system and a threshold value of 7 was $100 \%$ specific 


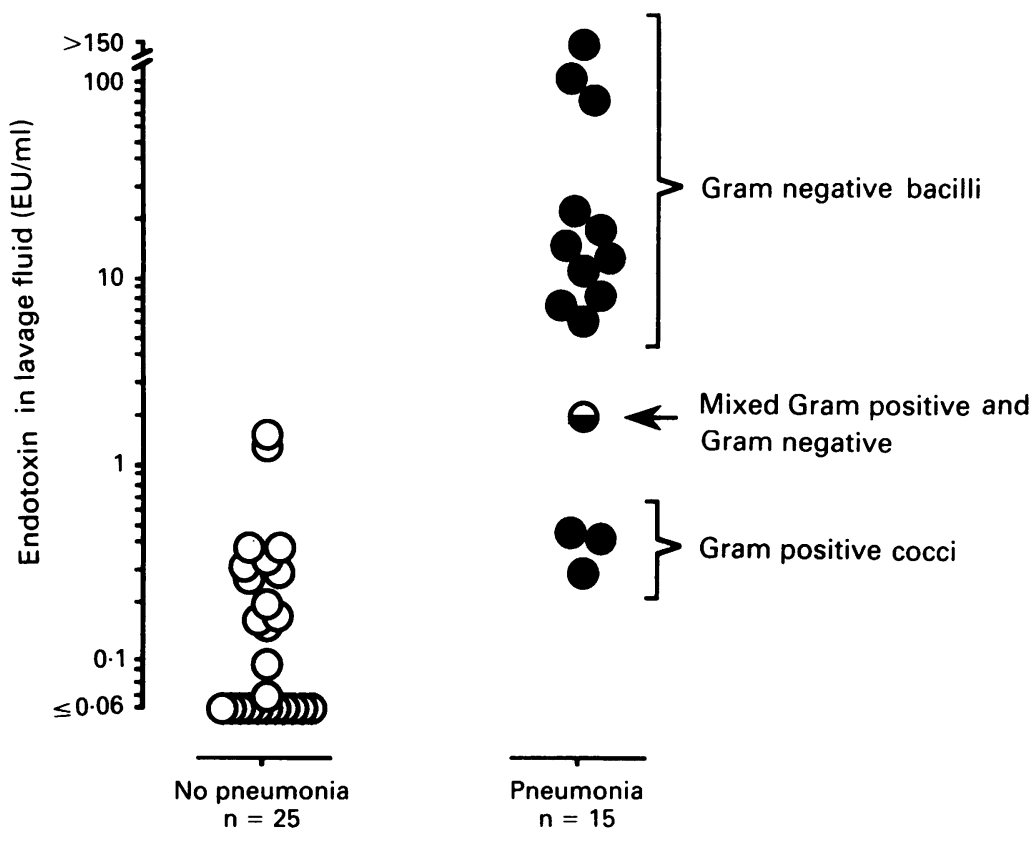

Endotoxin content (endotoxin unit $/ \mathrm{ml}$ ) of 40 bronchoalveolar lavage fluid specimens obtained during mechanical ventilation in patients with and without pneumonia.

and $93 \%$ sensitive in detecting pneumonia previously in ventilated patients with significant numbers of bacteria in lavage fluid. A significant bacterial count was a culture result of over $10^{5} / \mathrm{ml},{ }^{37}$ defined as a bacterial index.

For bacterial culture and quantification, $50 \mu \mathrm{l}$ of lavage fluid was inoculated with a Spiral Plater (Spiral Plater Instruments Inc, Bethesda, Maryland) on chocolate, colistinnalidixic acid, McConkey, and sheep blood agar and incubated in 5\% carbon dioxide for 72 hours. Endotoxin content was determined blindly on batched lavage fluids by the chromogenic Limulus assay (Coatest, KabiVitrum, Küsnacht, Switzerland). Lavage fluid was thawed, centrifuged, diluted (1:5, $1: 25,1: 125)$, and incubated with the proenzyme of Limulus lysate and chromogenic substrate $\$ 2423$ was added. Endotoxin causes a specific and quantitative activation of the proenzyme, resulting in a yellow coloration. Optical densities were compared with standard curves of Escherichia coli 055:B5 endotoxin. The limit of detection is 0.06 endotoxin unit $/ \mathrm{ml}$ $(=5 \mathrm{pg} / \mathrm{ml})^{4}$; no further dilutions were performed for levels above 150 endotoxin unit/ ml.

Statistical analysis was by the MannWhitney $U$ test and linear regression by the method of least squares.

\section{Results}

Of the 40 lavage fluid samples analysed, 25 were obtained from 15 intubated patients without clinical, radiological, or bacteriological evidence of pulmonary infection. The remaining 15 samples were collected during 15 episodes of ventilator associated pneumonia in 13 patients (11 patients had one episode and 2 patients had two episodes). A clear predomi- nance of Gram negative bacteria was observed in 11 of these 15 samples, with $\geqslant 10^{4}$ colony forming units/ml of Pseudomonas, enterobacteria, or Haemophilus influenzae in 10 of the 11 episodes. Two patients had bacteraemia and the same bacteria were cultured in blood and lavage fluid. In one episode of pneumonia there were equal numbers of Gram positive and Gram negative organisms, with $1.4 \times 10^{2}$ of $H$ influenzae. Three patients had a predominance of Gram positive bacteria, with small numbers $\left(\leqslant 10^{2}\right.$ colony forming unit $/ \mathrm{ml}$ ) of Gram negative bacteria. The mean clinical pulmonary infection score was 9.8 points in the patients with pneumonia (range 7-12) and 3.9 (range 1-6) in the patients without pneumonia.

A correlation was found between the quantity of Gram negative bacteria cultured and endotoxin levels in lavage fluid $(r=0.88$, $p<0.0001)$. The endotoxin level was $\geqslant 6 \mathrm{EU} /$ (median 15) $\mathrm{ml}$ in all 11 patients with Gram negative pneumonia. Non-infected patients $(n=25)$ and patients with predominantly Gram positive $(n=3)$ or mixed ventilator associated pneumonia $(n=1)$ had endotoxin levels below 2 (median 0.17) $\mathrm{EU} / \mathrm{ml}$ $(\mathrm{p}<0.0001$ in the comparison with Gram negative bacterial pneumonia)-see figure.

\section{Discussion}

Rapid diagnosis of ventilator associated pneumonia is important to allow specific treatment to begin as early as possible. In intubated patients bacteriological surveillance with regular cultures of tracheal aspirate is sensitive but has poor specificity. ${ }^{2}$ Bronchoalveolar lavage or protected brush cultures have a better yield, but may be of limited value during local ${ }^{8}$ or parenteral ${ }^{910}$ antibiotic treatment, where false negative cultures are frequent. Elastin fibres or polymorphonuclear cells containing intracellular bacteria in lavage fluid smears predict pulmonary infection in ventilated patients ${ }^{710}$ but lack sensitivity. ${ }^{7}$ Thus the ideal technique for detecting and quantifying the presence of bacteria in lavage fluid should be reliable, discriminative, rapid, and unaffected by antibiotic treatment.

In the present study we describe a discriminative method to diagnose Gram negative pneumonia during mechanical ventilation that provides quantitative results within two hours of sampling. Our data suggest that an endotoxin level $6 \mathrm{EU} / \mathrm{ml}$ or more in bronchoalveolar lavage fluid is of value for making an early diagnosis.

We thank the staff of the laboratory of bacteriology of the University Hospital of Geneva for expert technical assistance.

1 Fagon J-Y, Chastre J, Domart Y, Trouillet JL, Pierre J, Darne C. Nosocomial pneumonia in patients receiving continuous mechanical ventilation. Prospective analysis of 52 episodes with use of a protected specimen brush and quantitative culture techniques. Am Rev Respir Dis 1989;139:877-84.

2 Torres A, Puig de la Bellacasa J, Xaubet A, Gonzalez J, Rodriguez-Roisin R, Jimenez de Anta MT, et al. Diagnostic value of quantitative cultures of bronchoalveolar lavage and telescoping plugged catheter in mechanically ventilated patients with bacterial pneumonia. Am Rev Respir Dis 1989;140:306-10. 
3 Johanson WG, Seidenfeld JJ, Gomez P, De Los Santos R, Coalson JJ. Bacteriologic diagnosis of nosocomial pneumonia following prolonged mechanical ventilation. Am Rev Respir Dis 1988;137:259-64.

4 Van Deventer SJH, Buller HR, tenCate JW, Sturck A, Pauw W. Endotoxinaemia: an early predictor of septicaemia in febrile patients. Lancet 1988;i:605-8.

5 Stumacher RJ, Kovnat MJ, McCabe WR. Limitation of the usefulness of the limulus assay for endotoxin. $N$ Engl $J$ Med 1973;288:1261-4.

6 Elin RJ, Hosseini J. Clinical utility of the limulus amebocyte lysate (LAL) test. Progr Clin Biol Res 1985;189:307-27.

7 Pugin J, Auckenthaler R, Mili N, Janssens JP, Lew PD, Suter PM. Diagnosis of ventilator-associated pneumonia by bacteriologic analysis of bronchoscopic and non- bronchoscopic "blind" bronchoalveolar lavage fluid. $\mathrm{Am}$ Rev Respir Dis 1991;143:1121-9.

8 Gastinne H, Wolff M, Lachatre G, Boiteau R, Savy FP. Antibiotic levels in bronchial tree and serum during selective digestive decontamination. Intens Care Med 1991;17:215-8.

9 Smith BR, LeFrock JL. Bronchial tree penetration of antibiotics. Chest 1983;83:904-8.

10 Chastre J, Fagon J-Y, Soler P, Bornet M, Domarty Y, Trouillet JL, et al. Diagnosis of nosocomial bacterial pneumonia in intubated patients undergoing ventilation: comparison of the usefulness of bronchoalveolar lavage and protected specimen brush. Am J Med 1988;85:499506.

\section{Surgery at the Brompton Hospital in 1932-3}

I spent one year, November 1932 to November 1933, as the surgical resident at the Brompton Hospital, though at that time I was committed to a career in medicine, having within the previous 12 months become an MRCP and proceeded to $M D$ while working at the hospital in medical jobs at what would now be SHO level. It may seem odd that a post that would now be earmarked for trainee surgeons, and much sought after by those aiming for a specialised career in surgery, was then held by an aspiring physician. In the early 1930s the work at the Brompton, which had been founded as a hospital for consumption but had spread its interests to include chest diseases generally, was predominantly medical. Surgical intervention in chest disease had expanded only in the previous 10 years from little more than draining of empyemas to increasing use of various collapse procedures in pulmonary tuberculosis and of surgery within the open thorax, which had become a practicable proposition as a result of advances in anaesthesia based on experience in the first world war. In the late 1920 s lobectomy by a rather crude "snare" technique had been introduced in the treatment of localised bronchiectasis, and began to be attempted for a few cases of lung cancer. Removal of mediastinal tumours had become acceptably safe. Chronic empyema and lung asbscess were frequent problems. Surgical procedures required to deal with chronic empyema might be complex and formidable. External drainage was often considered an option in the treatment of lung abscess, and was a two stage procedure, requiring the preliminary production of pleural adhesions.

Because facilities for this sort of surgery were limited to specialist centres, many rare and complex cases were referred to the Brompton for consideration of surgical treatment. The two surgeons, JEH Roberts and Tudor
Edwards, were the leaders of thoracic surgery in London. They shared 30 surgical beds and one junior resident. Until 1935 the title of this post was assistant resident medical officer, and the holder of it was a physician in training. It was because it offered the possibility of experience of such a wide range of clinical problems, and because it seemed to me that it was the surgeons rather than the physicians who were moving into new territory, that I took the post.

The year for which I held this post was perhaps the busiest of my life. I was solely responsible for preoperative investigation, operative assistance, and, with the surgical ward sister, postoperative care as well as record keeping for the patients in 30 very active surgical beds, plus the not inconsiderable number under the care of the surgeons in the paying patients' wards. There was no one at what would now be surgical registrar or senior registrar level. There was no specialised postoperative or intensive care area, all patients returning directly from the theatre to the ward, where the surgical ward sister was a key figure; without her the entire set up would have collapsed. At the beginning of the year the two surgeons each had a voluntary clinical assistant-Clem Price Thomas for Tudor Edwards and Tim Nelson for JEH Roberts. During the year these were elected to the staff as assistant surgeons, so that I had four surgeons to look after. My successor in this post developed pulmonary tuberculosis towards the end of his year. I do not know how far this influenced the decision, when eventually in 1935 it was recognised that this job was one for a trainee surgeon, that two resident surgical officers were needed to do the work previously done by one assistant resident medical officer! 